\title{
Taming the Beast: Harnessing Blockchains in Developing Country Governments
}

\author{
Raúl Zambrano* \\ Independent Researcher, International Development Expert, New York, NY, United States
}

Amid pressing demands to achieve critical sustainable development goals, governments in developing countries face the additional complex task of embracing new digital technologies such as blockchains. This paper develops a framework interlinking development, technology, and government institutions that policymakers and development practitioners could use to address such a conundrum. State capacity and democratic governance are introduced as drivers in the overall analysis. With this in hand, blockchain technology is revisited from the perspective of governments in the Global South, identifying in the process key traits and proposing a new typology. An overview of the status of blockchain deployments in the Global South follows, complemented by a closer look at country examples to distill trends, patterns and risks. The paper

OPEN ACCESS

Edited by: Jane Thomason, University of Queensland, Australia

Reviewed by:

Carlos Santiso, Inter-American Development Bank,

United States

Beth Kewell,

University of Exeter, United Kingdom

${ }^{*}$ Correspondence:

Raúl Zambrano

rau@ictdegov.org

Specialty section: This article was submitted to Blockchain for Good,

a section of the journal

Frontiers in Blockchain

Received: 23 May 2019 Accepted: 09 December 2019

Published: 08 January 2020

Citation:

Zambrano R (2020) Taming the Beast: Harnessing Blockchains in Developing

Country Governments.

Front. Blockchain 2:27.

doi: 10.3389/fbloc.2019.00027 closes with a discussion of the findings, highlighting both challenges and opportunities for governments. It also provides basic guidance to development practitioners interested in enhancing current programming using blockchains as an enabler.

Keywords: blockchains, developing countries, public goods, sustainable development, digital government, state capacity, democratic governance, ICTD

\section{INTRODUCTION}

The last 30 years have witnessed a long wave of almost unstoppable digital innovation. The Internet led the way rapidly giving birth to the World Wide Web that proved to be a game-changer on a global scale. A wide variety of Internet-based applications such as e-commerce and e-government, to name a few, saw the light soon thereafter. By the end of the first decade of this century, mobile technologies and social media were already an integral part of the digital landscape. Artificial Intelligence and Machine Learning underwent a somewhat unexpected renaissance while Bitcoin and its underlying technology, blockchain, were loudly welcomed as the new kids on the block.

With few exceptions, developing countries have been recipients of the latest technological innovations-designed and produced for the most part by industrialized countries. Adopting and adapting the latest digital incarnations have been undertaken by both private and public initiatives in the Global South (Cozzens and Thakur, 2014). Almost in parallel, global development agendas such as the 2000 Millenium Development Goals (MDGs) and, since 2015, the Sustainable Development Goals (SDGs) established a series of targets that all UN member states agreed to achieve by 2030. Juggling these two seemingly independent agendas has been challenging for developing countries, especially for those where socio-economic and political gaps are the largest and fiscal and other key resources are relatively scarce.

Countries in the Global South are by now familiar with the incessant demands for change propelled by the various so-called "digital revolutions." Many national and even regional 
governments have taken action in one way or another to harness the potential benefits of new digital technologies. While pilots and on the ground digital initiatives pushed by the private sector and international donors have proliferated since the late 1990s, governments in many countries, reacting at a slow pace, focused mostly on policy and strategy development. Initially, countries designed and endorsed national Information and Communication Technologies (ICTs) for Development strategies (Rahman, 2001). By the beginning of this century, complementary or standalone e-Government strategies gained traction and provided the public sector with a roadmap to modernize the state sector, improve its efficiency and responsiveness, and scale-up the provision of public goods and basic services (Ndou, 2004).

While a few industrialized nations are already working on this, today not one single developing country has developed a national blockchain strategy. In contrast, several countries from the Global South have already completed Artificial Intelligence strategies (Dutton, 2018). Nevertheless, developing countries became the preferred test-beds for many of the first Bitcoin and blockchain technology pilots, starting in 2015 (Zambrano, 2017). History is thus seemingly repeating itself by following the usual cycle of innovation diffusion in developing contexts (Zanello et al., 2016). Here, blockchain technology has not made a difference when compared to previous "digital revolutions."

Within this context, this paper develops a conceptual framework to explore how governments and the public sector in developing countries ${ }^{1}$ can effectively harness blockchain technology to tackle key development challenges. The paper first presents an analytical framework that brings together technology, development and state capacity. It then presents an overview of blockchain technology from that perspective and delimits its scope accordingly. The third section reviews the current status of research on blockchains and development and blockchains in governments, complemented by an examination of relevant on the ground examples. The paper then presents a discussion of the proposed framework and research findings.

The focus of this paper is on blockchain technology as a generic platform that could help achieve international and national development goals endorsed by governments. The monetary and financial implications of the technology are thus not part of the analysis.

\section{CONCEPTUAL FRAMEWORK}

While the links between development and ICTs have been vastly explored as shown below, introducing state capacity into the equation adds a new dimension that delimits the role of the public sector and showcases the relevance of democratic governance in the overall developmental process.

\footnotetext{
${ }^{1}$ For the purposes of this paper, developing countries are not assumed to be a monolith. Instead, the concept includes nation-states that are at various stages of development as measured for example by the World Bank country income or lending categories, or the UNDP human development index, among others. Furthermore, development is a moving target as countries can and should travel across the various development categories in the medium-term, with some even transferring into the industrialized-country team, eventually.
}

\section{Sustainable Development}

While much older than ICT for Development (ICTD), the development field has changed dramatically in the last 30 years. Economic growth, usually equated with economic development, ruled unchallenged in the early years and used standard metrics such as GDP to gauge progress. While some metrics are still widely used today, challenges to the traditional economic development approach started to emerge first in the 1970s when environmental considerations and impact were brought to the forefront (Meadows et al., 1972).

By the end of the 1980s, the concept of sustainable development was coined by the Brundtland Commission running under the auspices of the United Nations (World Commission and on Environment Development., 1987). This led to the 1992 United Nations Earth Summit in Rio de Janeiro, where member states agreed to the implementation of Agenda 21 (United Nations, 1994). UN meetings to take stock on the implementation of the agenda took place every 5 years after its approval.

The 2000 Millennium Declaration and ensuing MDGs complemented Agenda 21 but focused primarily on poverty reduction, gender equality, and health pandemics (United Nations, 2000). Finally, the SDGs brought together Agenda 21 and MDGs under one single umbrella. Unlike its predecessor, the SDGs are universal and thus suited for all countries, both developed and developing (United Nations, 2015b). However, the number of goals, targets, and indicators grew almost exponentially. The SDGs comprise 17 goals, 169 targets, and 232 indicators ${ }^{2}$.

Many of the goals and targets set by the MDGs were not reached in many developing countries (United Nations, 2015a). Moreover, they included a set of targets and indicators calling for increased ICT access and diffusion. The SDGs, on the other hand, mainstreamed technology into several of the many targets established (Janowski, 2016) while largely avoiding using the ICT acronym in the final list of goals, targets, and indicators (United Nations, 2015c).

Sustainable development is defined as the intersection of three core pillars: economic growth, social inclusion, and environmental protection. The concept is usually represented using a Venn diagram, where the various intersections are labeled with unique names. Conspicuously absent here is governance, which is also a cross-cutting pillar that interacts with the other three. Nevertheless, the SDGs directly highlight its importance via Goal 17 which explicitly addresses core governance issues such as institutional building, the rule of law, participation, transparency, and accountability.

Given recent claims that blockchain is an "institutional technology" (Davidson et al., 2017), governance must be placed at the core for assessing the potential impact of digital technologies such as blockchains on sustainable development efforts.

\section{State Capacity}

As governments are the main focus of this paper, introducing the issue of state capacity is fundamental.

${ }^{2}$ Nine indicators are used more than once for different targets thus increasing the overall total to 241 . 
Recent research shows that state capacity played a key role in the achievement of the MDGs targeting poverty reduction (Asadullah and Savoia, 2018). Countries with low state capacity were less successful than those that were better equipped with capable institutions to support the provision of public goods. Moreover, a higher state capacity also helped sustain the gains made in the mediumterm, whereas those with weaker capacity were prone to short-term reversals.

The fact that there is no universal consensus on a definition of state capacity is just a reflection of its multidimensional character and complexity (e.g., Hau, 2012). For the purposes of this paper, however, state capacity is defined by the following traits (based on Savoia and Sen, 2015):

1. Institutional capacity: Capacity to design and implement development policies and programs, including the provision of public goods, as well as the legal capacity to sustain the rule of law in the long run. A professional and qualified civil service, along with "rules of the game" for public institutions for efficient and transparent running are part of the equation.

2. Fiscal capacity: Capacity to capture financial resources in a sustained fashion via taxation and other sources including external ones.

3. Infrastructural capacity: Ability to carry out institutional and fiscal responsibilities in all the territories under their control of the state. Includes Weber's well-known state monopoly over the means of violence or military capacity.

From a governance perspective, three issues are pertinent. First, distinguishing between state capacity and political regimes is essential. Strong states are frequently seen as a proxy for authoritarian or non-democratic regimes. However, most Western democracies have states with high capacity, while many non-democratic regimes operate with little to no institutional development (Tilly, 2007a) thus having to use force and repression to support existing regimes.

Second, democratic governance regimes can only be sustained over the long haul if a high capacity state is in place. Indeed, "democracy is a verb" (Tilly, 2007b), which is saying that such a political regime is not stationary but rather the locus of dynamic contention among different sets of actors and groups. De-democratization processes can indeed take place as has in fact occurred in the last 20 years throughout the world. The rise of populism, nationalism and some forms of proto-fascism in this period provides the necessary evidence.

Finally, states also need to have the necessary capabilities to harness new technologies, especially new ones such as blockchains and Artificial Intelligence that have a relatively high degree of complexity. This capacity, however, is not limited to technical knowledge, which is important, but also demands institutional capacity to develop successful policies and support on the ground initiatives, directly or indirectly via third parties, including the private sector.

However, the same technologies that help provide basic public goods to vulnerable and excluded populations can also be used to support de-democratization processes. This is the conundrum that developing countries must address as they deploy digital technologies.

All in all, state capacity is both a means to achieve development goals and a development goal in itself, particularly if resilient and long-term democratic regimes are part of the core goals. Nevertheless, state capacity has rarely been considered when studying the links between ICTs, development, and governments (e.g., Estevez and Janowski, 2013).

\section{ICTs and Development ICT for Development}

The field of ICT for development (ICTD) has been around for almost 40 years (Walsham, 2017) and continues to evolve. While several competing theories and schools of thought have already emerged (Zheng, 2015), the field still faces three critical and interconnected challenges. First and perhaps most obvious, is the link between ICT and development which boils down to the question of how exactly do ICTs foster development (Heeks, 2010; Zheng et al., 2018). It is regularly assumed that digital technologies automatically accomplish this, regardless of how the latter is defined.

The second and closely related to the former is the lack of solid evidence on the actual impact of ICTs in developmental processes (Foster and Heeks, 2014; Brown and Skelly, 2019). Estonia and South Korea are cited as examples of success but they are more the exception than the rule. Finally, the field has a bias toward technology and infrastructure (Gomez, 2013). This is perhaps best reflected by the marked emphasis placed on the "digital divide" combined with concurrent global calls for connecting the next billion users (Andreasson, 2015).

From a practitioners perspective, these three core challenges are closely related. Access to digital technologies automatically empowers people who can then take matters into their own hands and propel human and sustainable development in the mediumterm. Measuring impact is thus based on metrics centered on access to and use of the new technologies (ITU, 2016).

Any resemblance with a trickle-down theory of digital development is not coincidental. Furthermore, current evidence does not provide support for such a theory. In effect, the rapid evolution of digital technologies such as the Internet and social media, have yet make a dent on development according to recent research (Comin and Mestieri, 2018). The same goes for mobile technologies that have spread globally at an unprecedented pace ${ }^{3}$.

For the purposes of this paper, ICTs are instead deemed to be enablers of development processes (Zambrano and Eymann, 2014). ICTs have the potential to amplify existing programs and initiatives, bring new solutions to old problems and foster democratic governance and institutions. Such potential should be harnessed by local actors and institutions who acting in concert can bring positive change forward. On the flip side, new ICTs also generate new challenges that might demand attention.

\footnotetext{
${ }^{3}$ It is essential to distinguish here between ICTD and the ICT sector. The latter has grown exponentially since the late 1990s and propelled economic growth in industrialized countries (McKinsey, 2011). Countries such as India, South Korea, Taiwan and China have also been able to successfully develop relatively large ICT sectors.
} 
Blockchain technology squarely falls into this framework but also goes beyond the digital divide and connectivity approaches. Blockchains work as long as people are connected but, unlike other digital technologies, are not destined to promote increased access to the Internet and close the digital divide.

\section{ICTs in Government}

The implementation of development agendas at all levels is in itself a challenge for developing countries where state capacity is incipient. Adding new technologies to the equation might complicate matters more.

On the other hand, developing country governments should not attempt to drive development agendas on their own. Here, the distinction between private and public goods is crucial ${ }^{4}$. In the case of private goods and services, the private sector, big and small, should take the lead. Governments should have adequate institutional, legal, and infrastructural capacity to ensure this is possible and, if market failures are pervasive, create incentive mechanisms to attract the required capital and human resources.

Nevertheless, governments should take the helm to guide the modernization of the public sector and the universal provision of public goods. The former is the entry point to increase state capacity, in a sustained manner ${ }^{5}$. The latter, which depends to a large extent on state capacity, fills development gaps that fall right into the purview of government. Governance provides a third pillar. State modernization and public goods service provision should be designed and implemented within a democratic governance framework where the rule of law, participation, transparency, and accountability are core drivers that permeate all of society.

\section{Digital Government}

Developing countries are no strangers to the deployment and use of digital technologies within governments. Over 20 years ago, E-government appeared in the scene and rapidly spread to most countries. As mentioned above, many developing countries ended up designing e-government strategies. Despite repeated failures (Heeks, 2005), initiatives did not fizzle out. Furthermore, the concept has evolved since, from e-Government to eGovernance, Transformational Government, Lean Government, Open Government, Smart Government, Digital Government, and Intelligent Governments, among others (Janssen and Estevez, 2013; Millard, 2018).

This paper uses digital government broadly defined as public investments on ICTs to modernize the public sector, increase state capacity, and scale-up the provision of public goods. For developing countries where democratic regimes prevail, bringing into the equation the democratic governance approach mentioned above is critical. In this context, the net outcome of successful ICT investments in public institutions should not be limited to access, efficiency and effectiveness. More relevant are the strengthening of democratic institutions where transparency and accountability shine the most and citizen and stakeholder engagement becomes part of daily life.

\footnotetext{
${ }^{4}$ As discussed in Zambrano (2017).

${ }^{5}$ But not necessarily an increase in state size.
}

Figure 1 presents the three pillars of digital government and its interconnections.

For developing country democracies, the key entry point is engagement with stakeholders to define policy agendas, identify key challenges, and prioritize interventions. Governments should then be able to identify the public entities that need to be involved according to existing legal mandates. Allocation of public resources is then finalized and changes in the provision of selected public goods should eventually improve. Stakeholders can then provide feedback and demand changes and improvements.

Sequencing between these pillars is also essential. For example, governments cannot start implementing e-service delivery if they have not first developed adequate internal ICT and human capacity, and updated or modernized existing business processes. However, nothing is preventing governments from starting with service delivery or ignore the co-creation phase and the engagement with stakeholders.

While the diagram emphasizes the " $e$ " aspect of each pillar, the cycle can also take place without having ICTs in each of them. This is especially true for the participation and service delivery pillars. Instead, a multichannel approach is most suited in many cases, particularly in countries where ICT penetration is low and poverty is still pervasive.

This is a critical caveat as, in principle, where binding consultation is institutionally required, governance instances should be in place for stakeholder participation to have any meaningful impact on policies and agenda setting, regardless of the size of the "digital divide."

\section{CHARACTERIZING BLOCKCHAIN TECHNOLOGY FOR THE PUBLIC SECTOR}

The truth machine (Casey and Vigna, 2018). The trust machine (The Economist, 2015). The Internet of value (Tapscott and Tapscott, 2016). These are some of the names coined by different authors, academic and pundits to capture the complexity of the technology in one phrase. While catchy, they fall short from elucidating the benefits of the technology from a public sector perspective.

Almost 10 years after its birth, publication after publication continues to explore ways to explain the inner workings of the technology to the average person (e.g., Williams, 2019). Technology diffusion does not depend on the level of technology comprehension by the public (Kapoor et al., 2014).

In this section, blockchain technology is characterized from the perspective of the public sector in developing countries, using the conceptual framework presented in the previous section as a guide.

\section{Revisiting Blockchain, Again}

A blockchain is a digital ledger supported by the smart integration of three existing technologies: peer-to-peer (distributed) networks; cryptography; and consensus algorithms. Blockchain technology complexity stems in part from the fact that its 


\section{e-Participation}

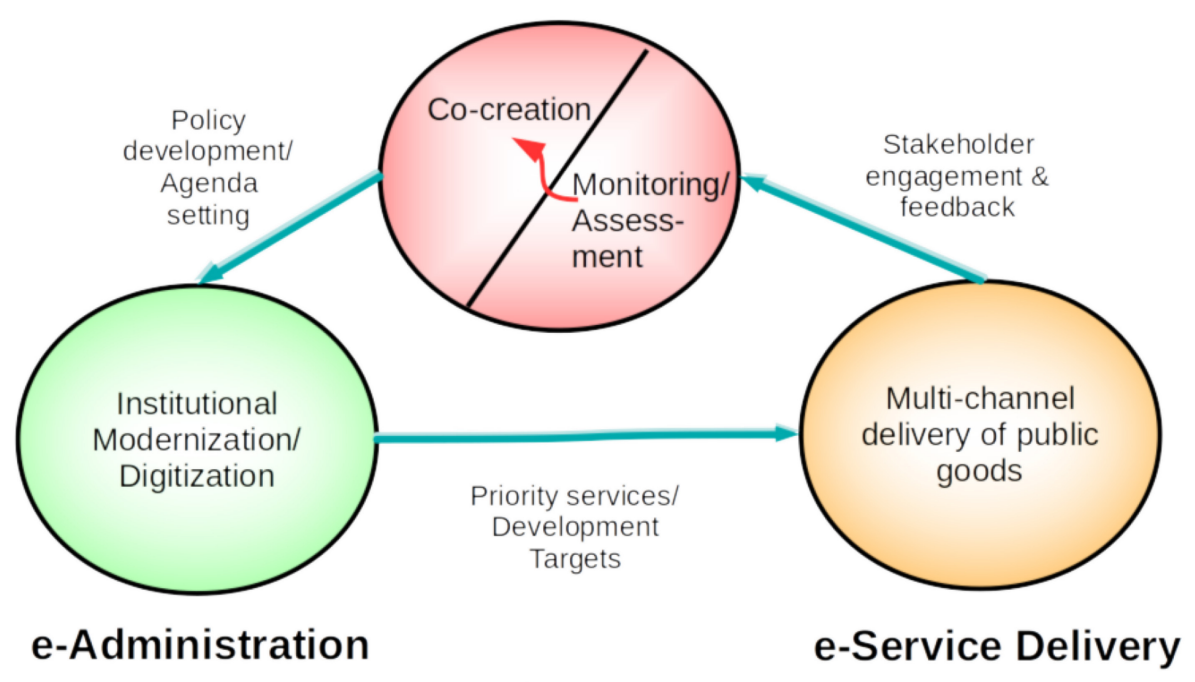

FIGURE 1 | The pillars of digital government.

supporting technologies have been hanging out at the fringes of the global network.

While the concept of digital raises little doubt, the same cannot be said about the ledger nature of blockchains. Despite the increasing popularity of spreadsheets, accountants are perhaps the group most familiar with ledgers as they continuously use them for business purposes. In that world, ledgers are analog or digital books where a series of transactions, mostly credits and debits, are sequentially recorded. Not surprisingly, some have suggested that blockchains are indeed a form of triple accounting (Simoyama et al., 2017; Taylor, 2017). Being that as it may, the key point here is that blockchains are not part of the relational database technology family. Blockchains are thus not designed to store big data, for example.

Moreover, and unlike traditional accounting ledgers, blockchain technology provides an open avenue for skilled users to write native computer code. Developing applications that operate within the platform or interact with external sources and resources is thus a key feature. Usually presented under the umbrella of smart contracts, programming in blockchains is not limited to them, as discussed below.

The underlying peer-to-peer or distributed network should not be confused with a decentralized one. Although the terms are used as synonyms in much of the literature, the latter allows for local centralization. That is, a group of nodes close together depend on central local one which in turn provides the link to other node clusters operating under similar arrangements. In a truly distributed network like blockchain, all nodes are equal and live independently.

One and two-way encryption tools are extensively used in blockchains. The first is known as hashing and creates an irreversible and unique digital signature for every transaction, a group of transactions, and blocks added to the existing chain.
The second is asymmetric public key cryptography that generates public and private keys for end users. Users share their public keys while keeping their private keys in a safe space, digital or analog. Most of the data recorded on a blockchain are thus comprised of hashes and public keys.

Two types of consensus take place in blockchain technology (Beyer, 2019). The first one occurs when the specialized nodes working on adding a new block of transactions to the chain, the so-called miners, agree on which transactions should be included in such block. This is known as Nakamoto consensus. The second happens when the new block of transactions is actually added to the chain. Here, any node or network user can validate such a block and agree to append it to the existing chain ${ }^{6}$.

In sum, a blockchain is a programmable digital layer operating within a distributed network, requiring cryptographic tools for access and transaction management, and using consensus algorithms for adding or appending new blocks of transactions to the ledger.

\section{Key Traits}

A vast literature on the key traits of blockchain technology already exists. This section presents key blockchain traits based on the contribution that each of its three underlying technologies furnishes. Two different sets of traits emerge. One stems from the unique contribution of each of the base technologies. The other is the result of the integration and interaction among them.

Table 1 summarizes the key traits accordingly.

Traits in the matrix diagonal represent standalone contributions. All other boxes are the result of the integration of the three technologies.

\footnotetext{
${ }^{6}$ Validation is almost instantaneous as all it requires is the multiplication of the unique hash identifying the previous block by the nonce (number used once) provided by the node (miner) requesting the addition of the new block.
} 
TABLE 1 | Blockchain technology core traits.

\begin{tabular}{llll}
\hline & P2P network & Cryptography & $\begin{array}{l}\text { Consensus } \\
\text { algorithms }\end{array}$ \\
\hline P2P network & Resilience & $\begin{array}{l}\text { Consensus/ } \\
\text { Transparency }\end{array}$ & $\begin{array}{l}\text { Consensus/ } \\
\text { Transparency }\end{array}$ \\
Cryptography & $\begin{array}{l}\text { Consensus/ } \\
\text { Transparency }\end{array}$ & Pseudonymity & Security \\
$\begin{array}{l}\text { Consensus } \\
\text { algorithms }\end{array}$ & $\begin{array}{l}\text { Consensus/ } \\
\text { Transparency }\end{array}$ & Security & Immutability/ \\
\hline
\end{tabular}

Standalone traits include:

Resilience: In a distributed network, multiple independent copies of the blockchain can co-exist. There is thus no central point of failure.

Pseudonymity: Cryptographic tools enable users to interact with others without having to reveal their real identities or providing any personal data. A relatively high degree of privacy thus exists. The same however does not apply to transactions that in principle can be viewed by anyone in the network.

Immutability: Blocks of transactions in the chain are timestamped and mathematically linked in sequential order. Changing one block thus requires changing all other blocks.

Incentives: Processing transactions and adding new blocks to the chain brings financial benefits to nodes involved (miners). Transaction fees and cryptocurrency rewards are the most common forms of income.

Traits stemming from the integration of the technologies include:

Consensus: Transaction processing and block addition are validated by network nodes in all cases. This is algorithmic consensus that should not be confused with humanbased consensus.

Transparency: User interactions and the resulting data can be viewed by any network member. Confidential information or data has no place here.

Security: Resilience, immutability, and consensus substantially increase the level of internal blockchain security. While still possible, hacking and network attacks are still possible.

\section{Typology}

Different types of blockchains have emerged since the technology first saw the light of day wearing a large Bitcoin/cryptocurrency hat. The standard way of classifying blockchains relies on the distinction between private and public, alongside permission levels. In this perspective, three different blockchain types emerge public, private, and consortium blockchains (e.g., Thompson, 2018). While relevant for the private sector, such differentiation might not be as effective from a public sector perspective. Furthermore, one potential issue with such typology is the lack of clear differentiation between the link/network and the application layers of the technology.
The distinction between private and consortium blockchains hinges in part on how many entities control access to the application layer. From the viewpoint of governments, having a so-called "private blockchain" in the public sector might not be the best way to promote the technology, given current demands for increased transparency and accountability. Governments can also have multiple institutions involved in the deployment of one blockchain platform-as could be the case for government interoperability, is one of the main staples of digital government. Calling such an arrangement a consortium does not add any value from the public sector perspective.

The best way to avoid such potential pitfalls is to go back to the three core blockchain technologies described in section Revisiting Blockchain, Again and suggest an alternative typology that caters to the specific idiosyncrasies of the public sector. For starters, peer-to-peer networks operate at the link/network layers and can be either open or closed. Users either find the door open and walk right in or must first ring the doorbell to be able to enter.

Cryptographic tools and consensus algorithms operate at the application layer. Nodes or users accessing such layers are first authenticated and then furnished an authorization to perform specific actions - such as creating a smart contract, mining the blockchain network or developing a Dapp, for example.

Table 2 depicts the matrix of options by separating the different layers.

Note that blockchains require all users to be authenticated, regardless of access type. The difference between open and closed network access depends on how users are authenticated. In the case of open access, users self-authenticate by creating pairs of public/private keys and digital signatures that uniquely identify them. In the case of closed access, a third-party (one or more entities) issues the authentication credentials using cryptographic tools. Note that open access authentication does not fulfill know-your-customer (KYC) or anti-money-laundering (AML) regulations and thus might be less attractive to both governments and businesses bound by them ${ }^{7}$.

Once authenticated, nodes will be able to access the application layer. In the case of classic blockchain networks such as Bitcoin and Ethereum, authentication alone grants immediate access to the application layer. Authorization does not exist as a separate instance and thus, no central authority is required. In this case, access to the application layer is fully decentralized. But open access blockchain platforms can also limit access to such layer. Typically, this happens when the platform wants to limit the number of nodes that can mine transactions and/or add a new block. A hybrid open blockchain decentralizes the link/network later but centralizes access to some part of the application layer.

For closed access networks, both authentication and authorization are managed by a central outfit-one single entity (private, in the traditional scheme) or many working together (consortium). Access to the link/network and application layers is thus fully centralized. However, it is also possible that a closed blockchain platform provides all authenticated nodes full access

\footnotetext{
${ }^{7}$ In the cryptocurrency realm, KYC/AML services are provided in a centralized fashion by either coin exchanges or other specialized businesses associated. Governments however cannot outsource such functions so easily.
} 
TABLE 2 | Blockchains typology for the public sector.

\begin{tabular}{|c|c|c|c|}
\hline \multirow[b]{2}{*}{$\begin{array}{l}\text { Network } \\
\text { Access }\end{array}$} & \multirow[t]{2}{*}{ Authentication } & \multicolumn{2}{|c|}{ Authorization } \\
\hline & & Yes & No \\
\hline Open & Autonomous & $\begin{array}{l}\text { Hybrid open } \\
\text { Selected nodes, } \\
\text { one or more } \\
\text { parties in charge } \\
\text { (Sovrin, EOS) }\end{array}$ & $\begin{array}{l}\text { Decentralized } \\
\text { Open to all by } \\
\text { default } \\
\text { (Bitcoin, Ethereum) }\end{array}$ \\
\hline Closed & Granted & $\begin{array}{l}\text { Centralized } \\
\text { Selected nodes, } \\
\text { one or more } \\
\text { parties in charge } \\
\text { (Hyperledger, R3) }\end{array}$ & $\begin{array}{l}\text { Hybrid closed } \\
\text { Open to all } \\
\text { authenticated } \\
\text { nodes ("Govchains") }\end{array}$ \\
\hline
\end{tabular}

to the application layer. This might be relevant to public sector initiatives where all actors within a single ministry or in multiple ministries or public entities work together in a cross-sectoral initiative. The concept of "GovChains" might prove useful here. A GovChain is similar to a government dedicated network with secure links to external clients. A GovChain runs on such network but add functionality at the application layer.

Finally, this typology highlights the similarities between hybrid open and closed centralized blockchains. In both, the levels of authorization to the application layer are provided by a central outfit. However, since hybrid open networks do not control authentication, all nodes and users still have read access to the full blockchain. This is not the case in closed blockchain networks. The latter can also introduce more sophisticated access control schemes to assign different roles of nodes in the application layer.

\section{Smart Contracts}

Undoubtedly, smart contracts are one of the most touted blockchain features. While the idea itself dates from the end of last century (Szabo, 1997), blockchains created the platform for the actual implementation of the idea.

For example, Ethereum provides the software (Solidity) ${ }^{8}$ and platform (Ethereum Virtual Machine) ${ }^{9}$ to program and execute contracts ${ }^{10}$. In this fashion, transactions envisaged on a given agreement can be triggered at a pre-established date or by action taken by one of the parties involved. Contractual transactions are automatically executed and, since the parties have direct access to digital currency, payments occur smoothly.

\footnotetext{
${ }^{8}$ https://solidity.readthedocs.io/en/v0.5.7/

${ }^{9} \mathrm{https} / / /$ solidity.readthedocs.io/en/develop/introduction-to-smart-contracts. html\#index-6. Ethereum smart contracts have their own blockchain accounts which function in distinct fashion vis-a-vis user accounts.

${ }^{10}$ According to Ethereum, "Contracts" in Ethereum should not be seen as something that should be "fulfilled" or "complied with"; rather, they are more like "autonomous agents" that live inside of the Ethereum execution environment, always executing a specific piece of code when "poked" by a message or transaction, and having direct control over their own ether balance and their own key/value store to store their permanent state'. https://ethereum-homestead.readthedocs.io/ en/latest/contracts-and-transactions/account-types-gas-and-transactions.html
}

Smart contracts also come in different flavors (OSTechNix, 2019). The first one mirrors traditional legal contracts which can now be executed on a blockchain platform. Not limited to financial agreements (Murphy, 2018), these type of contracts have attracted most of the attention of both practitioners and academics (e.g., Macrinici et al., 2018). DAOs or Decentralized Autonomous Organizations come in second. Here, a given community agrees to specific governance arrangements which are then coded into a binding smart contract. DAOs suffered a devastating setback thanks to the well-known 2016 hack (Falkon, 2017) but are still being explored by practitioners and academics (e.g., Diallo et al., 2018).

Finally, Application Layer Contracts (ALCs) provide an interface between the blockchains and applications such as Dapps and the Internet of Things. Less well-known than the others, ALCs handle multiple smart contracts. Here, the line between contracts and regular computing programming starts to blur. ALCs resemble well-known software gateways that allow communication across different platforms at the application layer. Coding seems to become now a "contract" which in turn recalls "code is law" arguments (Dwyer, 2017; Yeung, 2019).

As with most nascent technologies, smart contracts have limitations. On the technology side, they are prone to coding errors and bugs as the DAO hack shows. This is exacerbated by the fact that programmers must translate legal contracts into code. Complex contracts might thus yield additional coding errors and bugs. As all nodes have to run and validate the code in smart contracts, code size is limited and thus running complex applications is not possible (O'Connell, 2019). Again, complex contracts might not be suitable for blockchain execution.

While smart contracts reduce transaction costs, which are now executed automatically, costs related to contract breaches, dispute resolution, and redress are much higher (Szczerbowski, 2018). Smart contracts are also immutable and act as autonomous agents. In this light, researchers recommend using a hybrid approach where both regular and smart contracts act in sync (Levi and Lipton, 2018).

The question on the legality of the first type of contracts has received plenty of attention (Frankenreiter, 2019; Waltl et al., 2019) Authors have argued that some smart contracts are compatible with current legislation, at least in a few industrialized countries (De Filippi and Wright, 2018). More generally, it seems that laws and regulations will need to be changed or updated.

In developing countries with weak state capacity and incipient rule of law institutions, this might become a major challenge.

\section{Blockchains Are Not a Monolith}

Since its inception, dynamic innovation, backed by top human talent with access to substantial financial resources, has been part of the blockchain ecosystem. The community has thus been able not only to tackle the initial limitations of the technology but also to enhance its core functionality. As seen above, blockchains come in many different formats and more are popping up by the day. This is a critical consideration for both academics and policymakers. Blockchain technology is not a monolith. On the contrary, blockchains are a moving target. 
Here, the distinction between blockchains and distributed ledger technologies (DLTs) is important (Dexter, 2018). Blockchains are a subset of DLTs. A blockchain is a DLT that mathematically links blocks of data in sequential fashion using cryptographic tools. A DLT is a digital ledger that runs on a distributed network and does not require the use of consensus algorithms for its full operation ${ }^{11}$.

\section{BLOCKCHAIN-ING GOVERNMENTS \\ Blockchains, Development, and Governments}

Just like its digital technology predecessors such as the Internet, both for-profit and non-profit innovators and practitioners continuously showcase the relevance of the new technology to tackle socio-economic, political, and environmental issues. Here, different layers and different labels appear in the scene.

The first layer, which in turn is the most generic, links blockchains to existing and emerging issues without necessarily referencing development or the SDGs-albeit the latter being universal. Labels used to describe this link include blockchain for social good (Podder and Venkat, 2018; BreakerMag, 2019), blockchain for social impact (Fernando, 2018), and blockchain for social change (Verlhust and Young, 2018), the latter being a research project. For example, the Blockchain for Social Impact Coalition (BSIC), spearheaded by a NY-based blockchain company, was launched in 2017. Comprised of close to 50 entities, BSIC mentions the SDGs but has set its own agenda ${ }^{12}$ For the most part, blockchain startups working under these labels take the initiative on their own and venture into the field to experiment with the nascent technology.

Pace Kewell ${ }^{13}$, a key issue with this set of initiatives is the lack of a rigorous definition of the concepts being put forward. Social good might have different meanings for different communities, more so if the work is undertaken on a global scale. Furthermore, social change and social impact can also be negative. That is, on the ground projects can also generate change and impact by exacerbating existing gaps despite the best efforts of those doing the implementation. Indicators and metrics to assess and measure change are missing in most of these efforts.

The second layer includes entities directly supporting the achievement of the SDGs. Three groups comprise this layer. The first works on a global scale and have advocacy and awarenessraising role. The Blockchain Commission, a partnership of three non-profit entities launched at the United Nations in 2017, is a typical example.

A second group includes UN agencies and development organizations that work in developing countries. UNDP and UNICEF, among many others, are good examples. These entities work on the ground and disburse their own resources as

\footnotetext{
${ }^{11}$ To be more precise, both blockchains and DLTs are part of the broader concept of distributed systems where consensus on how events are recorded is fundamental to ensure system consistency and stability (Lamport, 1978).

${ }^{12}$ https://blockchainforsocialimpact.com/about/

${ }^{13}$ Kewell et al. (2017) explored the links between blockchains and sustainable development using an affordances perspective, coining the term "blockchain for good" in the process.
}

grants to finance projects. UNICEF has launched an innovation fund which has over 15 million dollars to finance innovative blockchain projects in developing countries (Harry, 2017; UNICEF, 2018). UNDP allocates small grants from existing resources and finances pilots, usually in partnership with blockchain startups (UNDP, 2018). Note that these grants go to local innovators and entrepreneurs in developing and not to governments. Most entities working in the SDG realm select the goals and targets that reflect their own internal mandates. Reach and scale also play a role as covering 18 goals and over 200 targets does require considerable human and financial resources that most do not have.

Last but not least are the organizations working in the humanitarian space. This group also includes UN agencies as well as reputed organizations that have carried out this line of work for many years. While UN agencies such as the World Food Programme (WFP) ${ }^{14}$ operate in developing countries, this is not the case for many others. Perhaps surprisingly, one of the most well-known examples of apparent blockchain success occurred in this space thanks to WFP refugee program in Jordan (Juskalian, 2018; WFP, 2018), which is now expanding to other regions and thematic areas (Baydakova, 2018). A recent report details the various initiatives in this space while highlighting some lessons learned so far (Coppi, 2019).

While governments in developing countries are not one of the main overall targets of these groups, very few take a more comprehensive and strategic approach, or explicitly consider the provision of public goods by governments as is the case, for example, of the blockchain for social change research project (Verlhust and Young, 2018).

Development organizations such as the Center for Global Development, USAID, the International Development Research Center and the Institute for Development Studies generated reports aimed at understanding the potential development impact of blockchains (Hernandez, 2017; Pisa and Judden, 2017; Zambrano, 2017; Nelson, 2018; Pisa, 2018). These authors attempted to delimit the specific application of the emerging technology in the Global South while pushing back on the ongoing hype. The Asian Development Bank produced a report targeting Asia and provided recommendations based on the analysis of five use cases (Ferrarini et al., 2017), including digital identity, project-aid monitoring, and smart energy, all relevant to most developing countries.

More recently, an overall blockchain research review included an analysis of the relevance of the technology in the implementation of the SDGs (Hughes et al., 2019). The authors highlight the goals and targets where blockchains technology could have the most impact while providing a couple of use cases based on selected current development challenges India is facing today.

The current approach to deploy blockchains in support of development is centered on the elaboration of relevant use cases, which might be openly linked to development goals. Once completed, they are then pitched to social ventures, development

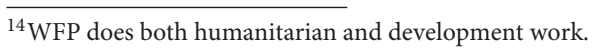


organizations or even governments in the Global South to secure either funding or support -or both-for small pilots.

Given the deluge of publications (and academic research) on the technology, the above examples show a giant gap when it comes to deploying blockchains in developing country governments. Furthermore, only a few of these directly link such deployments to digital government policies, strategies, and implementation agendas which, as reported by the United Nations (UNDESA, 2018), is ongoing in most countries, including developing nations.

The relationship between blockchains and digital government has thus attracted little attention and real case studies are for the most part missing in action ${ }^{15}$. Three distinct patterns can however be identified. First, blockchains are positioned as support infrastructure for ongoing e-government platforms and initiatives. Here, the emphasis is on the technology and innovation part of the equation, and not on the institutional benefits, thus drastically reducing its transformational potential Second, blockchains are seen as a threat, sometimes lethal, to public institutions as they seem to demand dramatic changes in the way they are run-to the point that might put their existence into question. And third, on the ground evidence from blockchain deployments within governments is incipient at best.

\section{Country Examples}

While many blockchain pilots and projects are taking place in developing countries, some even involving the public sector, only a few are actually led by governments. This subsection highlights some of these cases, bearing in mind that keeping track of all such initiatives is a complex task.

Estonia is often cited as a best practice for blockchain deployment (Sullivan and Burger, 2017; Guarda, 2018) and an example to follow. The country has managed to graduate to the developed country team in $<30$ years. Estonia gained its independence in 1991 and rapidly gained a legitimate reputation of a country able to harness ICTs to promote overall human development. E-governance became its main staple. Nowadays, the country provides assistance in this area to many others almost on a global scale.

The 2007 cyber-attacks on Estonia's overall infostructure opened the door for further innovation in the area of security. That same year a company called Guardtime was launched, offering government a solution called KSI (Keyless Service Infrastructure), which allowed for the decentralized verification of public records, data, and access points without having to use a digital signature. Instead, KSI uses one-way hashing and a decentralized ledger. Deployed in 2008, KSI does resemble blockchain technology sans one of its core components: consensus algorithms.

Being that as it may, the key point of the Estonia example is the role KSI played in supporting existing e-governance platforms

\footnotetext{
${ }^{15}$ Academic research, reviewed by the author, has the same gaps. For example, the latest literature review on the subject published last Summer was only able to identify twenty one relevant papers (Batubara et al., 2018). Only six were published in academic journals. Moreover, most of these papers take a sectoral approach focusing on topics such as electoral processes, healthcare, and education, to menton a few.
}

and services. It furnished a new solution to a major digital challenge that could perhaps not be solved otherwise. While the company claims it beat Nakamoto by a couple of years ${ }^{16}$, KSI is not in the same ballpark as Bitcoin or Ethereum ${ }^{17}$. Technological replication of the Estonia case using a different platform might thus be more complex than expected.

While not a country, Dubai is certainly larger in population than Estonia and hosts over 200 nationalities. The Dubai Emirate also operates almost like a city-state and has its own policies and institutions in addition to federal ones. Back in 2016, the Prime Minister of the Emirate announced the launching of a blockchain strategy planned to be fully implemented by 2020 (Gulf News, 2016). Spearheaded by Smart Dubai, a local entity that oversees the strategic deployment of new technologies and innovation in close collaboration with the private sector, the strategy set three core goals: foster government efficiency; create new business opportunities and startups; and assume a leadership position on blockchain technologies (Bishr, 2018).

In terms of efficiency, two key priorities have been identified: a paperless government and a blockchain-based payments system (Jones, 2018). Note that both themes were already part of the overall policy agenda of Smart Dubai, which also happens to host the Smart Dubai Government initiative ${ }^{18}$. The second theme focusing on startups is also part of the Smart Dubai agenda. More recently, Smart Dubai launched a decentralized open data initiative, yet another local priority previously identified, in partnership with a blockchain company (Andrikopoulos, 2019).

While getting updated information on the evolution of these projects is cumbersome, the core lesson from Dubai is similar to that of Estonia: blockchains are brought in to support existing digital government issues and priorities and are effectively deployed to address related challenges. But in the case of Dubai, the Emirate has developed a strategy and created an international multi-stakeholder board to oversee its implementation (Berryhill et al., 2018).

Kenya seems to be following these same steps. Early last year the government announced the creation of a blockchain task force under the leadership of the Ministry of ICT. The task force prepared a report which was submitted to the Minister last November. While the report is apparently not publicly, press reports suggest that its contents are fully aligned with Kenya's development priorities (Kenyan Wallstreet, 2018; Tanui, 2018). Perhaps coincidentally, the government announced a program to provide affordable housing a month before (Alexandre, 2018).

Countries such as Georgia and Peru have taken a more sectoral approach. Georgia is one of the leaders in the use of blockchains for land title registration which has already been the subject of critical academic research (Lemieux, 2017; Thomas, 2017). Recently, Peru announced a new government procurement system based on blockchain technology in partnership with a local blockchain startup and the Inter American Development Bank (IADB). Public procurement is one of the main sources of

\footnotetext{
$\overline{{ }^{16} \mathrm{https} / / / \text { guardtime.com/technology }}$

${ }^{17} \mathrm{KSI}$ can be stationed within the DLT rubric.

${ }^{18}$ Smart Dubai also spearheads the local Artificial Intelligence strategy among others.
} 
corruption and a traditional priority of e-government initiatives. IADB has launched a hemispheric initiative called LAC-Chain with the idea of supporting the deployment of the technology on its client countries (IDB, 2018).

In any event, neither of these two countries have an overall blockchain strategy. In principle then, the results and outcomes of ongoing sectoral initiatives can provide fertile ground for such development.

A counterexample for the developed world can also offer additional insights. Illinois became the first US state to embrace blockchain technology. Launched at the end of 2016, the initiative was part of the broader Smarter State initiative sponsored by the Department of Innovation and Technology. The blockchain project has three overall targets: increase government efficiency by integrating services; develop a local ecosystem; and modernize governance to handle a distributed economy (Illinois Blockchain Initiative, 2017). Pilots on land titles and self-sovereign identity were launched a few months later.

However, by the beginning of 2018, the project seems to have fizzled. The final report published February last year highlights the limitations of the technology, including the lack of successful pilots, scalability, interoperability, and lack of privacy (Van Wagenen, 2018). So while Illinois follows the same path as some countries discussed above, technical limitations seem to have prevented success. In addition, the fact that the project was requesting specific legislative changes at the state level might have also ruffled some feathers.

\section{DISCUSSION}

\section{Overview}

The intersections between development, ICTs and developing country governments provide the fodder for the conceptual framework developed in this paper. Figure 2 below depicts such interconnections. Governments play various roles when it comes to sustainable development and ICTs, and are not limited to the digital government sphere per se. But governments should lead to promote digital government within a sustainable development context.

On the flip side, the traditional approach to e-government centers on the relation between the public sector and technology while assuming development outcomes are either the natural

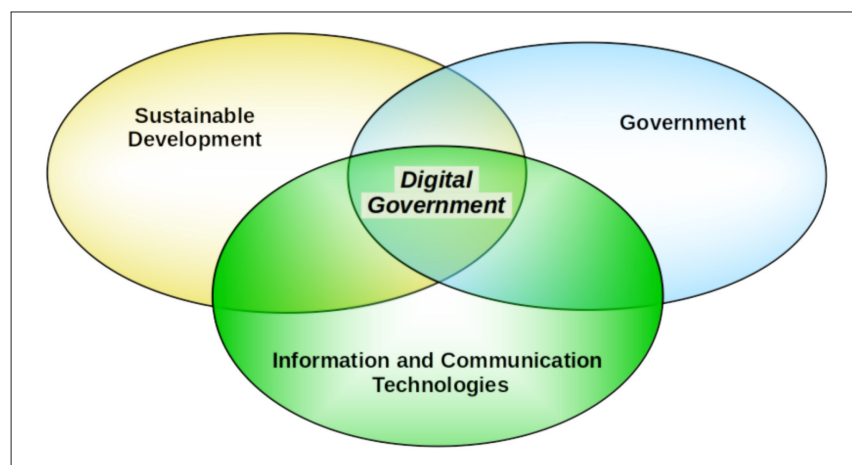

FIGURE 2 | Digital government in a development context. and automatic. For example, the standard e-government transactional approach that emphasizes G2B, G2C, and G2G interactions-depicted in Figure 2 by the intersection between government and ICTs, has limited scope for targeting specific development gaps as the onus is on interactions among key sectors and stakeholders.

Having governments as part and parcel of the overall equation also demands serious consideration of the relationship between state capacity and both development and digital technologies. The dynamics between these three can be complex, bearing in mind that sustainable development itself encompasses four pillars (governance included) while digital government comprises three, as discussed in section Conceptual Framework above. Nevertheless, the essential point is that state capacity is both a means to promote digital government and sustainable development and a goal in itself, as clearly established by the UN SDG agenda.

\section{Taming the Beast: Taking Stock}

For starters, and like most digital technologies, blockchains are exogenous to the national ecosystems of developing countries. Governments thus continuously play catch-up with such technologies. A core issue here is the lack of local capacity to effectively harness the new entrant, even if the platform is Open Source and thus has no per-user licensing costs. Such capacity is not merely technical but also scientific and managerial as governments and partners should fully comprehend the inner workings of the technology to, for example, launch public bidding processes calling for the adoption of blockchains to support specific digital government priorities or gaps. In this regard, blockchains are not at all different from previous digital technologies migrating into developing nations.

While the complexity of blockchains might add additional entry barriers, governments are probably better off focusing on both the three underlying technologies that support it and the different types of blockchains, DLTs included, that are available. Regarding the former, many countries in the Global South lack adequate cryptographic expertise, have weak public key infrastructures (PKIs) in place, and are not very familiar with consensus algorithms. Furthermore, while peer-to-peer networking is readily available, limited Internet access will surely pose constraints to widespread utilization.

As described in section Characterizing Blockchain Technology for the Public Sector above, developing country governments can choose among different types of blockchains and DLTs. However, the first question they need to ask is if blockchain technology is the most optimal solution for the issue at stake. Several models for making such a decision have already been developed (Rustum, 2019) and should be further refined to fit developing country contexts. Selecting the adequate platform will mostly depend on the type of digital government priority under the radar screen. It is however possible to conclude that, in general, governments should opt for private or closed blockchains (Atzori, 2015), hybrids included. KYC/AML issues are relevant here, particularly for the provision of public goods such as education, health, and justice which consume scarce public resources that should be optimally allocated. On the 
other hand, in terms of the dissemination of public documents, information, and data, public or open blockchains can provide the right vehicle as they guarantee immutability, integrity, and transparency while ensuring pseudonymous access-or access based on self-sovereign identity, if available.

The cases discussed in the country examples subsection yielded essential insights for deploying blockchains within governments. The evidence compiled so far, which is still incipient, suggests that the technology can deliver when explicitly linked to both digital government institutional instances and digital government priorities and gaps. For the most part, successful blockchain implementation in emerging countries have either complemented existing digital government platforms and initiatives or provided a new solution to vexing issues that could not be solved otherwise.

In both cases, the technology was not deployed in a standalone fashion. Integration with other digital technologies was also part of the process. This is perhaps a crucial point as blockchains seem to add real value when brought in as a new member of an existing technology team. In this light, it is possible to suggest that smart contracts could become really intelligent if they could effectively interact with Deep Learning algorithms and platforms, for example (Salah et al., 2019).

While not having a happy ending, the Illinois experience sheds light on the risks of deploying blockchains. Technical limitations of the blockchain platforms selected for the various pilots helped stall the project. The initiative also attempted to address its governance implications. Consequently, specific legislative changes were requested to the local assembly, including biometric-based notarization, self-notarization of documents and several other measures to improve the management of public land records (State of Illinois, 2018). While having potential for increasing state capacity, demands for institutional change, grounded mostly on technological grounds, might not take off if local decision-makers have not been involved in the process from the start. Surely, this is not unique to blockchains. But the fact that the technology is also touted as governance and institutional changer (e.g., Reijers et al., 2016), from centralized to distributed mechanisms, might end up strengthening local resistance to change.

\section{Harnessing Blockchains: Challenges and Opportunities}

As discussed in subsection Blockchains, Development and Governments, blockchain deployment in developing country governments is still in its infancy. Hype, complexity, lack of successful implementation, and an overemphasis on cryptocurrencies and new financial markets are factors that might help explain this state of affairs - not to forget the fact that blockchain technology is still maturing.

The conceptual framework presented in this paper targets this gap by providing governments and development practitioners with potential entry points to explore the effective deployment of blockchain technology systematically. If governments are the main target of blockchain technology initiatives, then digital government and state capacity must take center stage.
Early evidence suggests that blockchains can make a difference when aligned with existing digital government institutions, strategies, priorities, and platforms. This, in turn, indicates that a more nuanced approach to the interplay between blockchains and key digital government components is required.

For starters, governments in the Global South should capitalize on existing South-South and North-South cooperation agreements and networks to extract more information on ongoing blockchain deployments in the public sector. Collaboration across government peers on a global scale could add more value than published reports and thus help avoid pitfalls that pioneers in the sector have unexpectedly faced.

Looking at the way blockchains can tackle core digital government themes and bottlenecks will be as important, if not more. For example, government interoperability has traditionally been one of such issues. More often than not, public entities happen to run their own technology platforms that almost never talk to each other. On the other hand, citizens and stakeholders will surely benefit from having one-stop shops to undertake all the business they do with government. To reach this point, government platforms must be able to converse among themselves. Governments have thus developed government interoperability frameworks that promote public sector integration. This is accomplished by the development of digital gateways that mediate the conversations across different public platforms. Having a blockchain platform to support and enhance interoperability by ensuring the integrity and transparency of the public sector certainly has enormous potential (El-dosuky and El-adl, 2019). The same goes for many of the other core areas of traditional e-government.

Blockchains can also have potential in enhancing state capacity. Many developing countries have designed decentralization or devolution strategies where both policymaking and fiscal management shifts from central governments to those in regions, states, and municipalities. Implementation of such policies has however been challenging, particularly in low-income countries. Lack of overall capacity has been one of the main challenges local governments face accompanied by a potential decrease in fiscal resources. Enter blockchains. For example, governments could set up one blockchain platform, a GovChain, to cater to all local governments. Financial resources could thus flow within the Gov-chan vis smart contacts, while local government offices can use the platform to support other government activities such as public information disclosure. This is an area that might have great potential but remains largely unexplored (De Santis, 2019).

Along the same lines, it is possible to make a case for distributed policymaking. Many developing countries are characterized by socio-economic, cultural and geographical diversity that comprehensive national policies tend to ignore for the sake of universality. At the same time, many countries also have national, regional, and local development plans that, for the most part, are not necessarily in sync. Finding a middle of the road approach where local diversity shines but, at the same time, falls within broader development policies set at higher levels of government is feasible. Again, a GovChain could make a key difference here. 
While complex, the challenges for adopting blockchains in the public sector of developing countries are not insurmountable. On the other hand, the opportunities are just starting to popup and could be harnessed in the short-term if the links between technology, sustainability and government institutions are brought to the fore.

\section{CONCLUSION}

Developing countries are, for the most part, playing catch-up when attempting to harness the latest digital technologies such as blockchains, among many others. This set of countries has also endorsed internationally-agreed development goals while devising their own national and subnational development plans. While juggling such agendas is not simple, governments can play an important role in promoting the link between technology and development while enticing all other actors and sectors to act in concert. Undoubtedly, governments should lead when it comes to the modernization of public institutions, the deployment of digital government and the provision of public goods.

This paper develops a conceptual framework aimed at grasping the dynamics between sustainable development, governments in the Global South and ICTs, introducing state capacity as both a means and an end. State capacity is required to achieve the various development goals and harness ICTs effectively. Building state capacity is also a goal that will ensure development gains can be sustained in the long haul. The framework is then used to assess the relevance of blockchain technologies in such dynamics ${ }^{19}$.

While still technologically evolving, blockchains offer unique traits and benefits that could make a difference if deployed strategically within governments in developing countries. Unfortunately, on the ground evidence of blockchain implementation is still emerging while a closer examination of its relationship with digital government is almost absent. Use cases still dominate the scene and the core assumption is that blockchains will prevail as the overall disruptor with no partners in sight.

\footnotetext{
${ }^{19}$ The conceptual framework suggested by the paper can also be used to study the introduction of other digital technologies such as Artificial Intelligence in the public sector of developing countries.
}

\section{REFERENCES}

Alexandre, A. (2018). Kenyan gov't to use blockchain in new affordable housing project. Cointelegraph. Available online at: https://cointelegraph.com/news/ kenyan-govt-to-use-blockchain-in-new-affordable-housing-project (accessed October 16, 2018).

Andreasson, K. J. (ed.). (2015). Digital Divides: The New Challenges and Opportunities of e-Inclusion. Boca Raton, FL: CRC Press, Taylor \& Francis Group. doi: 10.1201/b17986

Andrikopoulos, V. (2019). "Decentralised and open data turns Dubai into a smart city | outlier ventures," in Outlier Ventures | Investing in Blockchain. AI \& IoT Tech (blog). Available online at: https://outlierventures.io/research/ decentralised-and-open-data-turns-dubai-into-a-smart-city/ (accessed May 6, 2019).
However, early evidence suggests that blockchains can add value when deployed as part of a team of digital technologies working in sync. Early implementations also indicate that adequate institutional support and endorsement are critical, especially from the public entities promoting digital government that had already identified a range of priorities as key targets. Nevertheless, risks still abound, stemming from the limitations of the technology itself and its complexity, and calls for rapid institutional change which could push back existing political will. In addition, issues related to implementation costs and actual project management need further exploration.

The distributed nature of blockchain technology and its implications for governance systems has also upstaged digital government concerns. Indeed, blockchains have been touted as an "institutional technology" that could bring dramatic changes within governments (and all other sectors), propelling new governance mechanisms mostly based on smart contracts. While linked to ongoing discussions on algorithmic governance concerning Artificial Intelligence and all its cousins, a blockchain-based perspective connecting these dots is missing in action.

Developing countries with low capacity states and nascent capitalist development might find such new governance options less palatable given pressing sustainable development demands and calls to sustain democratic governance regimes. If it is a real institutional technology, then blockchain technology should be a critical enabler for innovative institutional development. Blockchains could also deliver the goods within existing institutional settings, thus making institutional change a matter of human agency, not technology. And that would undoubtedly be a critical achievement that could contribute to resilient longterm sustainable development.

\section{DATA AVAILABILITY STATEMENT}

Publicly available datasets were analyzed in this study. This data can be found here: https://publicadministration.un.org/egovkb/ en-us/Reports/UN-E-Government-Survey-2018.

\section{AUTHOR CONTRIBUTIONS}

The author has created all the content on this paper.

Asadullah, M. N., and Savoia, A. (2018). Poverty reduction during 1990-2013: did millennium development goals adoption and state capacity matter? World Dev. 105, 70-82. doi: 10.1016/j.worlddev.2017. 12.010

Atzori, M. (2015). Blockchain Technology and Decentralized Governance: Is the State Still Necessary? SSRN Scholarly Paper ID 2709713. Rochester, NY: Social Science Research Network. Available online at: https://papers.ssrn.com/abstract=2709713. doi: 10.2139/ssrn.27 09713

Batubara, F. R., Ubacht, J., and Janssen, M. (2018). "Challenges of blockchain technology adoption for e-government: a systematic literature review." in Proceedings of the 19th Annual International Conference on Digital Government Research: Governance in the Data Age (New York, NY: ACM). doi: $10.1145 / 3209281.3209317$ 
Baydakova, A. (2018). UN food program to expand blockchain testing to african supply chain. CoinDesk (blog). Available online at: https://www.coindesk.com/ un-food-program-to-expand-blockchain-testing-to-african-supply-chain (accessed September 26, 2018).

Berryhill, J., Bourgery, T., and Hanson, A. (2018). Blockchains Unchained. OECD Working Papers on Public Governance, no. 28, 1-52. doi: 10.1787/3c32c429-en

Beyer, S. (2019). Proof-of-Work Is Not a Consensus Protocol: Understanding the Basics of Blockchain Consensus. Medium. Available online at: https:// medium.com/cryptronics/proof-of-work-is-not-a-consensus-protocolunderstanding-the-basics-of-blockchain-consensus-30aac7e845c8 (accessed April 1, 2019).

Bishr, A. B. (2018). Dubai: a city powered by blockchain. Innovations $12,4-8$. doi: 10.1162/inov_a_00271

BreakerMag (2019). 73 blockchain social good organizations that are actually doing something. BREAKERMAG (blog). Available online at: https://breakermag. com/73-blockchain-social-good-organizations-that-are-actually-doingsomething/ (accessed February 1, 2019).

Brown, A. N., and Skelly, H. J. (2019). How much evidence is there really? Mapping the evidence base for ICT4D interventions. Inform. Technol. Int. Dev. 15:18.

Casey, M., and Vigna, P. (2018). The Truth Machine: The Blockchain and the Future of Everything, 1st Edn. New York, NY: St. Martin's Press.

Comin, D., and Mestieri, M. (2018). If technology has arrived everywhere, why has income diverged? Am. Econ. J. 10, 137-78. doi: 10.1257/mac.20150175

Coppi, G. (2019). Blockchain and Distributed Ledger Technologies in the Humanitarian Sector. ODI. Available online at: https://www.odi.org/ publications/11284-blockchain-and-distributed-ledger-technologieshumanitarian-sector (accessed February 1, 2019).

Cozzens, S., and Thakur, D. (2014). Innovation and Inequality: Emerging Technologies in an Unequal World. Cheltenham, UK: Edward Elgar Pub.

Davidson, S., De Filippi, P., and Potts, J. (2017). Blockchains and the Economic Institutions of Capitalism. SSRN Scholarly Paper ID 3221527. Rochester, NY: Social Science Research Network. Available online at: https://papers.ssrn.com/ abstract $=3221527$.

De Filippi, P., and Wright, A. (2018). Blockchain and the Law: The Rule of Code. Cambridge, MA: Harvard University Press.

De Santis, R. (2019). Is There a Future for Blockchain in Local Government? Available online at: https://icma.org/blog-posts/there-future-blockchainlocal-government (accessed February 19, 2019).

Dexter, S. (2018). Blockchain vs DLT (Distributed Ledger Technology). Mango Research (blog). Available online at: https://www.mangoresearch.co/ blockchain-vs-distributed-ledger-technology-dlt/ (accessed February 20, 2018).

Diallo, N., Shi, W., Xu, L., Gao, Z., Chen, L., Lu, Y., et al. (2018). "EGovDAO: a better government using blockchain based decentralized autonomous organization," in 2018 International Conference on EDemocracy EGovernment (ICEDEG), (Houston, TX), 166-71. doi: 10.1109/ICEDEG.2018.8372356

Dutton, T. (2018). An Overview of National AI Strategies. Politics + AI (Blog). Available online at: https://medium.com/politics-ai/an-overview-of-nationalai-strategies-2a70ec6edfd

Dwyer, R. (2017). Code != Law: Explorations of the Blockchain as a Mode of Algorithmic Governance. Available online at: https://www.academia.edu/ 34734732/Code_Law_Explorations_of_the_Blockchain_as_a_Mode_of_ Algorithmic_Governance

El-dosuky, M. A., and El-adl, G. H. (2019). GIZAChain: e-government interoperability zone alignment, based on blockchain technology. PeerJ Preprints 7:e27477v1. doi: 10.7287/peerj.preprints.27477v1

Estevez, E., and Janowski, T. (2013). Electronic governance for sustainable development - conceptual framework and state of research. Govern. Inform. Q. 30, S94-109. doi: 10.1016/j.giq.2012.11.001

Falkon, S. (2017). The story of the DAO - its history and consequences. Medium (blog). Available online at: https://medium.com/swlh/the-storyof-the-dao-its-history-and-consequences-71e6a8a551ee (accessed December 24, 2017).

Fernando, A. (2018). Interested blockchain for social impact? Here are the projects you should know. Medium (blog). Available online at: https://medium.com/ @00AaronFernando/interested-blockchain-for-social-impact-here-are-theprojects-you-should-know-8c14926e4f88 (accessed May 29, 2018).
Ferrarini, B., Maupin, J., and Hinojales, M. (2017). Distributed Ledger Technologies for Developing Asia. Manila: Asian Development Bank. doi: 10.22617/WPS179184-2

Foster, C., and Heeks, R. (2014). Why efforts to spread novel ICTs often fail. Appr. Technol. 41, 59-61.

Frankenreiter, J. (2019). The limits of smart contracts. J. Inst. Theor. Econ. 175, 149-162. doi: 10.1628/jite-2019-0021

Gomez, R. (2013). The changing field of ICTD: growth and maturation of the field, 2000-2010. Electron J. Inform. Syst. Dev. Count. 58, 1-21. doi: 10.1002/j.1681-4835.2013.tb00408.x

Guarda, D. (2018). How Governments in Sweden, Denmark and Estonia Are Adopting Blockchain and AI. Available online at: https://www.intelligenthq. com/innovation-management/how-governments-are-adopting-blockchainand-ai-in-advanced-economies-part-2/ (accessed December 14, 2018).

Gulf News (2016). Dubai Launches Blockchain Strategy to Become Paperless by 2020. Available online at: https://gulfnews.com/uae/government/dubailaunches-blockchain-strategy-to-become-paperless-by-2020-1.1907790 (accessed October 5, 2016)

Harry (2017). Blockchain commission \& blockchain for impact launched at UN to advance the sustainable development goals. CultHub (blog). Available online at: https://www.culthub.com/pr/blockchain-commission-blockchain-forimpact-launched-at-un-to-advance-the-sustainable-development-goals/9176 (accessed September 26, 2017).

Hau, M. V. (2012). "State capacity and inclusive development: new challenges and directions," in Global Development Institute Working Paper Series. esid-002-12 (GDI, The University of Manchester). Available online at: https://ideas.repec. org/p/bwp/bwppap/esid-002-12.html

Heeks, R. (2005). E-government as a carrier of context. J. Public Policy 25, 51-74. doi: $10.1017 /$ S0143814X05000206

Heeks, R. (2010). Do information and communication technologies (ICTs) contribute to development? J. Int. Dev. 22, 625-40. doi: 10.1002/jid.1716

Hernandez, K. (2017). Blockchain for Development - Hope or Hype? Available online at: https://opendocs.ids.ac.uk/opendocs/handle/123456789/12945

Hughes, L., Dwivedi, Y. K., Misra, S. K., Rana, N. P., Raghavan, V., and Akella, V. (2019). Blockchain research, practice and policy: applications, benefits, limitations, emerging research themes and research agenda. Int. J. Inform. Manag. 49, 114-29. doi: 10.1016/j.ijinfomgt.2019.02.005

IDB (2018). Global Alliance to Promote the Use of Blockchain in Latin America and the Caribbean I IADB. Available online at: https://www.iadb.org/en/ news/global-alliance-promote-use-blockchain-latin-america-and-caribbean (accessed October 30, 2018).

Illinois Blockchain Initiative (2017). Illinois Blockchain Initiative: Insights, Progress \& Horizon Scanning. The Illinois Blockchain Initiative. Available online at: https://illinoisblockchain.tech/illinois-blockchain-initiative-insightsprogress-horizon-scanning-61e25a51e345 (accessed March 24, 2017).

ITU (2016). Core List of Indicators. Available online at: https://www.itu.int/en/ ITU-D/Statistics/Pages/coreindicators/default.aspx (accessed March 25, 2019).

Janowski, T. (2016). Implementing sustainable development goals with digital government - aspiration-capacity gap. Govern. Inform. Q. 33, 603-13. doi: 10.1016/j.giq.2016.12.001

Janssen, M., and Estevez, E. (2013). Lean government and platformbased governance-doing more with less. Govern. Inform. Q. 30, S1-8. doi: 10.1016/j.giq.2012.11.003

Jones, M. (2018). Smart dubai launches blockchain-based payments for government. The Block (blog). Available online at: https://www. blockchaintechnology-news.com/2018/09/24/smart-dubai-launchesblockchain-based-payments-for-government/ (accessed September 24, 2018).

Juskalian, R. (2018). Inside the Jordan Refugee Camp That Runs on Blockchain. MIT Technology Review. Available online at: https://www.technologyreview.com/s/ 610806/inside-the-jordan-refugee-camp-that-runs-on-blockchain/ (accessed April 12, 2018).

Kapoor, K. K., Dwivedi, Y. K., and Williams, M. D. (2014). Rogers' innovation adoption attributes: a systematic review and synthesis of existing research. Inform. Syst. Manag. 31, 74-91. doi: 10.1080/10580530.2014.854103

Kenyan Wallstreet (2018). Kenya govt sets up blockchain \& artificial intelligence taskforce!. Kenyan Wallstreet (blog). Available online at: https:// 
kenyanwallstreet.com/kenya-govt-sets-blockchain-artificial-intelligencetaskforce/ (accessed January 16, 2018).

Kewell, B., Adams, R., and Parry, G. (2017). Blockchain for good? Strat. Change 26, 429-37. doi: 10.1002/jsc.2143

Lamport, L. (1978). Time, clocks, and the ordering of events in a distributed system. Commun. ACM 21, 558-565. doi: 10.1145/359545.359563

Lemieux, V. L. (2017). Evaluating the use of blockchain in land transactions: an archival science perspective. Eur. Prop. Law J. 6, 392-440. doi: 10.1515/eplj-2017-0019

Levi, S. D., and Lipton, A. B. (2018). An Introduction to Smart Contracts and Their Potential and Inherent Limitations. Available online at: https://corpgov. law.harvard.edu/2018/05/26/an-introduction-to-smart-contracts-and-theirpotential-and-inherent-limitations/ (accessed May 26, 2018).

Macrinici, D., Cartofeanu, C., and Gao, S. (2018). Smart contract applications within blockchain technology: a systematic mapping study. Telemat. Inform. 35, 2337-54. doi: 10.1016/j.tele.2018.10.004

McKinsey (2011). Internet Matters: The Net's Sweeping Impact on Growth, Jobs, and Prosperity | McKinsey. Available online at: https://www.mckinsey.com/ industries/high-tech/our-insights/internet-matters (accessed March 26, 2019).

Meadows, D., Meadows, D., Randers, J., and Behrens, W. W. III. (eds.). (1972). The Limits to Growth: A Report for the Club of Rome's Project on the Predicament of Mankind. New York, NY: Universe Books. doi: 10.1349/ddlp.1

Millard, J. (2018). Open governance systems: doing more with more. Govern. Inform. Q. 35 (4 Suppl.), S77-87. doi: 10.1016/j.giq.2015. 08.003

Murphy, J. (2018). Five Non-Financial Blockchain Use Cases Marketers Need To Understand. Forbes. Available online at: https://www.forbes. com/sites/forbescommunicationscouncil/2018/03/27/five-non-financialblockchain-use-cases-marketers-need-to-understand/ (accessed March 27, 2018).

Ndou, V. (2004). E-government for developing countries: opportunities and challenges. Electron. J. Inform. Syst. Dev. Count. 18, 1-24. doi: 10.1002/j.1681-4835.2004.tb00117.x

Nelson, P. (2018). Primer on Blockchain - How to Assess the Relevance of Distributed Ledger Technology to International Development. Available online at: https://www.usaid.gov/digital-development/digital-finance/Blockchainprimer (accessed April 15, 2019).

O'Connell, J. (2019). Ambisafe Co-founder on the Limits to Coding Smart Contracts. Available online at: http://cryptographicasset.com/ambisafe-co-founder-onthe-limits-to-coding-smart-contracts/ (accessed April 19, 2019).

OSTechNix (2019). Blockchain 2.0 - explaining smart contracts and its types [Part 5]. OSTechNix (blog). Available online at: https://www.ostechnix.com/ blockchain-2-0-explaining-smart-contracts-and-its-types/ (accessed March 28, 2019).

Pisa, M. (2018). Reassessing Expectations for Blockchain and Development. Center For Global Development. Available online at: https://www.cgdev. org/publication/reassessing-expectations-blockchain-and-development-costcomplexity (accessed May 17, 2018).

Pisa, M., and Judden, M. (2017). Blockchain and Economic Development: Hype vs. Reality. Center For Global Development. Available online at: https://www. cgdev.org/publication/blockchain-and-economic-development-hype-vsreality (accessed July 20, 2017).

Podder, S., and Venkat, S. (2018). Blockchain: A Powerful Tool for Social Good. HuffPost. Available online at: https://www.huffpost.com/entry/blockchaina-powerful-tool-for-social-good_b_5a4e7f8ae4b0f9b24bf315a0 (accessed January 4, 2018).

Rahman, H. (2001). Developing Successful ICT Strategies: Competitive Advantages in a Global Knowledge-Driven Society. IGI Global. Available online at: https:// www.igi-global.com/book/developing-successful-ict-strategies/260

Reijers, W., O’Brolcháin, F., and Haynes, P. (2016). Governance in blockchain technologies \& social contract theories. Ledger 1, 134-151. doi: 10.5195/LEDGER.2016.62

Rustum, A. (2019). DLT access control comparison. B9lab Blog. Available online at: https://blog.b9lab.com/dlt-access-control-comparison-ble8c69b953d (accessed February 5, 2019).

Salah, K., Rehman, M. H. U., Nizamuddin, N., and Al-Fuqaha, A. (2019). Blockchain for AI: review and open research challenges. IEEE Access 7, 10127-10149. doi: 10.1109/ACCESS.2018.2890507
Savoia, A., and Sen, K. (2015). Measurement, evolution, determinants, and consequences of state capacity: a review of recent research. J. Econ. Surv. 29, 441-58. doi: 10.1111/joes. 12065

Simoyama, F. D. O., Grigg, I., Luiz Pereira Bueno, R., and Cavarzere De Oliveira L. (2017). Triple entry ledgers with blockchain for auditing. Int. J. Audit. Technol. 3, 163-83. doi: 10.1504/IJAUDIT.2017.086741

State of Illinois (2018). House Joint Resolutiom 25 - Illinois Blockchain and Distributed Ledger Task Force: Final Report to the General Assembly. Available online at: https://www2.illinois.gov/sites/doit/Strategy/Documents/ BlockchainTaskForceFinalReport020518.pdf (accessed March 08, 2019).

Sullivan, C., and Burger, E. (2017). E-residency and blockchain. Comp. Law Sec. Rev. 33, 470-81. doi: 10.1016/j.clsr.2017.03.016

Szabo, N. (1997). Formalizing and securing relationships on public networks. First Monday 2. doi: 10.5210/fm.v2i9.548

Szczerbowski, J. J. (2018). Transaction Costs of Blockchain Smart Contracts. Law Forensic Sci. 16

Tanui, C. (2018). The Kenya blockchain taskforce concludes its report. Kenyan Wallstreet (blog). Available online at: https://kenyanwallstreet.com/the-kenyablockchain-taskforce-concludes-report-on-blockchain-technology/ (accessed November 19, 2018).

Tapscott, D., and Tapscott, A. (2016). Blockchain Revolution: How the Technology behind Bitcoin Is Changing Money, Business, and the World. New York, NY: Portfolio/Penguin.

Taylor, B. (2017) Triple-Entry Accounting And Blockchain: A Common Misconception. Forbes. Available online at: https://www.forbes.com/sites/ forbesfinancecouncil/2017/11/28/triple-entry-accounting-and-blockchain-acommon-misconception/ (accessed April 3, 2019).

The Economist (2015). The Trust Machine. Available online at: https://www. economist.com/leaders/2015/10/31/the-trust-machine (accessed October 31, 2015).

Thomas, R. (2017). Blockchain's incompatibility for use as a land registry: issues of definition, feasibility and risk. Eur. Prop. Law J. 6, 361-90. doi: 10.1515/eplj-2017-0021

Thompson, C. (2018). The difference between a private, public \& consortium blockchain. Blockchain Daily News. Available online at: https://www.linkedin. $\mathrm{com} /$ pulse/difference-between-private-public-consortium-collin-thompson (accessed May 14, 2018).

Tilly, C. (2007a). Democracy. Cambridge; New York, NY: Cambridge University Press.

Tilly, C. (2007b). Grudging Consent. Washington, DC: The American Interest.

UNDESA (2018). UN E-Government Survey 2018. Available online at: https:// publicadministration.un.org/egovkb/en-us/Reports/UN-E-GovernmentSurvey-2018

UNDP (2018). The-Future-Is-Decentralised. UNDP. Available online at: https:// www.undp.org/content/undp/en/home/librarypage/corporate/the-future-isdecentralised.html

UNICEF (2018). UNICEF's Innovation Fund Announces First Cohort of Blockchain Investments in Emerging Markets. Available online at: https://www.unicef.org/ press-releases/unicefs-innovation-fund-announces-first-cohort-blockchaininvestments-emerging (accessed December 10, 2018).

United Nations (ed.). (1994). Agenda 21: Programme of Action for Sustainable Development; Rio Declaration on Environment and Development; Statement of Forest Principles; the Final Text of Agreements Negotiated by Governments at the United Nations Conference on Environment and Development (UNCED), 3 - 14 June 1992, Rio de Janeiro, Brazil. New York, NY: Department of Public Information.

United Nations (2000). United Nations Millennium Declaration. Available online at: https://www.un.org/en/development/devagenda/millennium.shtml

United Nations (2015a). Millennium Development Goals Report 2015. Statistical material. Available online at: mdg-report-2015.html (accessed July 6, 2015).

United Nations (2015b). Transforming Our World: The 2030 Agenda for Sustainable Development. Available online at: https://www.un.org/ga/search/ view_doc.asp?symbol=A/RES/70/1\&Lang=E

United Nations (2015c). Report of the Inter-Agency and Expert Group on Sustainable Development Goal Indicators. Available online at: https://unstats. un.org/unsd/statcom/47th-session/documents/2016-2-IAEG-SDGs-E.pdf

Van Wagenen, J. (2018). Illinois' First Blockchain Report Highlights Challenges and Opportunities of Adopting Tech. Technology Solutions That Drive 
Government. Available online at: https://statetechmagazine.com/article/2018/ 02/illinois-first-blockchain-report-highlights-challenges-and-opportunitiesof-adopting-tech (accessed February 21, 2018).

Verlhust, S., and Young, A. (2018). Field Report: On the Emergent Use of Distributed Ledger Technologies for Identity Management. Blockchange. Available online at: https://blockchan.ge/fieldreport.html (accessed April 14, 2019).

Walsham, G. (2017). ICT4D research: reflections on history and future agenda. Inform. Technol. Dev. 23, 18-41. doi: 10.1080/02681102.2016.1246406

Waltl, B., Sillaber, C., Gallersdörfer, U., and Matthes, F. (2019). "Blockchains and smart contracts: a threat for the legal industry?" in Business Transformation Through Blockchain, Vol. II, eds H. Treiblmaier and R. Beck (Cham: Springer International Publishing), 287-315. doi: 10.1007/978-3-319-99058-3_11

WFP (2018). Blockchain for Zero Hunger | WFP Innovation. Available online at: https://innovation.wfp.org/project/building-blocks (accessed March 12, 2018).

Williams, S. P. (2019). Blockchain: The Next Everything. New York, NY: Scribner. Available online at: https://www.simonandschuster.com/books/BlockchainThe-Next-Everything/Stephen-P-Williams/9781982116828

World Commission on Environment and Development (ed.) (1987). Our Common Future. Oxford Paperbacks. Oxford; New York, NY: Oxford University Press.

Yeung, K. (2019). Regulation by blockchain: the emerging battle for supremacy between the code of law and code as law. Modern Law Rev. 82, 207-39. doi: 10.1111/1468-2230.12399

Zambrano, R. (2017). Unpacking the Disruptive Potential of Blockchain Technology for Human Development. Available online at: https://www.idrc.ca/en/stories/ blockchain
Zambrano, R., and Eymann, S. (2014). "Crowdsourcing and human development: the role of governments," in Proceedings of the 8th International Conference on Theory and Practice of Electronic Governance, ICEGOV '14 (New York, NY: ACM), 170-177. doi: 10.1145/2691195.2691223

Zanello, G., Fu, X., Mohnen, P., and Ventresca, M. (2016). The creation and diffusion of innovation in developing countries: a systematic literature review. J. Econ. Surveys 30, 884-912. doi: 10.1111/joes.12126

Zheng, Y. (2015). "ICT4D, overview of theories in," in The International Encyclopedia of Digital Communication and Society (John Wiley and Sons, Ltd.), 1-10. doi: 10.1002/9781118767771.wbiedcs153

Zheng, Y., Hatakka, M., Sahay, S., and Andersson, A. (2018). Conceptualizing development in information and communication technology for development (ICT4D). Inform. Technol. Dev. 24, 1-14. doi: 10.1080/02681102.2017.1396020

Conflict of Interest: The author declares that the research was conducted in the absence of any commercial or financial relationships that could be construed as a potential conflict of interest.

Copyright (c) 2020 Zambrano. This is an open-access article distributed under the terms of the Creative Commons Attribution License (CC BY). The use, distribution or reproduction in other forums is permitted, provided the original author(s) and the copyright owner(s) are credited and that the original publication in this journal is cited, in accordance with accepted academic practice. No use, distribution or reproduction is permitted which does not comply with these terms. 